Article

\title{
Prevalence and Risk of Anisakid Larvae in Fresh Fish Frequently Consumed in Spain: An Overview
}

\author{
Ángela L. Debenedetti ${ }^{1}$, Elena Madrid ${ }^{1}$, María Trelis ${ }^{1}$, Francisco J. Codes ${ }^{1}$, \\ Florimar Gil-Gómez ${ }^{1,2}$, Sandra Sáez-Durán ${ }^{1}$ and Màrius V. Fuentes ${ }^{1, *(D)}$ \\ 1 Parasites and Health Research Group, Department of Pharmacy and Pharmaceutical Technology and \\ Parasitology, University of València, 46100 Burjassot, València, Spain; angela.debenedetti@uv.es (Á.L.D.); \\ elena.madrid@uv.es (E.M.); maria.trelis@uv.es (M.T.); Fjcodes_serrato@hotmail.com (F.J.C.); \\ florimargil@gmail.com (F.G.-G.); sandra.saez@uv.es (S.S.-D.) \\ 2 Laboratorio de Investigaciones Parasitológicas "Jesús Moreno Rangel”, Departamento de Microbiología y \\ Parasitología, Facultad de Farmacia y Bioanálisis, Universidad de Los Andes, 5101 Mérida, Venezuela \\ * Correspondence: mario.v.fuentes@uv.es; Tel.: +34-963-544-493
}

Received: 14 December 2018; Accepted: 7 February 2019; Published: 21 February 2019

check for updates

\begin{abstract}
Anisakidosis is a fish-borne zoonosis caused by parasitic nematodes of the family Anisakidae, of which the species belonging to Anisakis simplex complex are the most representative. It is considered an emerging disease in Spain. The objective of this study is to analyse the presence of larvae in fish frequently consumed in Spanish supermarkets, inferring the risk of infection. In total 1,786 specimens of 9 different fish species, from two geographical origins (Atlantic and Mediterranean), acquired fresh and not eviscerated were examined for anisakid nematodes. Analysis showed that $33.7 \%$ of the samples were parasitized by Anisakis larvae. The horse mackerel (Trachurus trachurus) presented the highest total prevalence $(66.0 \%)$, followed by the silver hake (Merluccius bilinearis) (59.5\%), the mackerel (Scomber scombrus) (58.4\%), the blue whiting (Micromesistius poutassou) (53.9\%) and the European hake (Merlucius merlucius) (45.0\%). In general, the prevalence was higher in Atlantic than in Mediterranean fish. In all the species analysed, a higher presence of the parasite was detected in the viscera than in the flesh, although in the most parasitized species a noteworthy prevalence and abundance was observed in the flesh. In conclusion, risk factors, like fish species and origin, should be considered by consumers, in addition of following the recommendations established by Commission Regulation (EU) No1276/2011 and the Spanish Royal Decree 1420/2006.
\end{abstract}

Keywords: human anisakidosis risk; Anisakis; blue whiting; hake; red mullet; mackerel; horse mackerel; chub mackerel; sardine; anchovy

\section{Introduction}

Anisakidosis is a fish-borne zoonosis caused by the ingestion of larval parasitic nematodes of the family Anisakidae, of which species from the Anisakis simplex complex are the most frequent. Humans, who are not suitable hosts for these parasites, acquire the infection accidentally by eating mainly raw, salted marinated or undercooked fish or cephalopods [1]. Apart from being the causal agent of a number of gastric, intestinal or ectopic form of pathology [2], Anisakis species are considered to be the only parasites in fishery products that are implicated in allergic reactions [3]. Once sensitization has occurred, response to parasite allergens can be acute and generate severe allergic symptoms [4]. On account of above mentioned anisakidosis is considered an emerging public health risk for consumers $[5,6]$.

Anisakis spp. larvae can be found parasitizing a wide range of marine teleost species inhabiting the Atlantic and the Mediterranean, as well as the Pacific to the Antarctic area, affecting the fish product 
quality [7]. In spite of the large number of studies focusing on the molecular and genetic identification of the parasite [8] and the potential differences in pathogenicity between sibling species [9], there is a scarce information concerning the spatial distribution of anisakid larvae in some economically important fish species [10], which makes it very difficult to ascertain the actual epidemiological status of the parasite and the repercussions on consumers.

The main source of infection are marine fish species as the main ingredient of raw dishes such as sushi, ceviche, sashimi and other similar foods [1]. Between 2000 and 2017 a total of 236 not imported cases was reported in the European Union. Spain, in particular, has the highest reported incidence in Europe and the second worldwide [11], with marinated anchovies in vinegar, a typical and very popular Spanish dish, being the main food vehicle of infection [6].

In order to prevent infection, the most effective measure is, according to the recommendations of the Commission Regulation (EU) No1276/2011 [12] and the Spanish Royal Decree 1420/2006 [13], avoiding the consumption of raw or undercooked fish or applying some treatments to inactivate the larvae. These treatments consist of: (1) cooking fish at an internal temperature of $60^{\circ} \mathrm{C}$ for at least $1 \mathrm{~min}$. or at $65^{\circ}$ for at least $30 \mathrm{~s}$; (2) freezing at $-20^{\circ} \mathrm{C}$ or below for at least $24 \mathrm{~h}$, although other authors recommend freezing at $-35^{\circ} \mathrm{C}$ for at least $15 \mathrm{~h}$ or at $-15^{\circ} \mathrm{C}$ for at least $96 \mathrm{~h}$, at the core of the fishery products [3]. Nevertheless, domestic freezers do not always provide a low homogenous temperature and are, therefore, not able to inactivate larvae. The freezing tolerance of these nematodes constitutes a safety risk when domestic freezers operating at low cooling capacity are used for the inactivation of these larvae, as temperatures are not sufficiently low or homogenous [14]. Particularly in the case of anchovies in vinegar, some experiments suggest that the consumption of pieces infected with A. simplex may be a potential hazard when consumed by sensitized individuals, even if the larvae are killed by freezing [15]. Consequently, the importance of minimizing the infection risk gains importance, which requires the establishment of preventive measures for consumers at the point of purchasing.

The present study analyses the presence of anisakid larvae in nine fish species sold at nationwide supermarkets in the metropolitan area of València, Spain. All these species are frequently consumed in Spain; some of them as part of typical dishes based upon marinated or raw fish as the main ingredient. The specific aims of this work are to assess the epidemiological status of anisakid larvae in fresh fish purchased in nationwide supermarkets, in order to determinate the potential risk of human anisakiosis through the consumption of these species. In addition, to study the influence of extrinsic (origin and season of capture) and intrinsic (weight and length of the fish) factors on the prevalence and abundance of the larvae. The results will shed light on the most important species that may be a source of infection, as well as the factors that affect the presence of the parasite. This knowledge will make it possible to propose measures consumers can apply in order to minimize the risk of diseases.

\section{Results}

Considering all the samples as a whole, a total of 663 specimens $(40.33 \%)$ were parasitized by $\mathrm{L}_{3}$ larvae of nematodes. After morphological identification, these larvae were classified as Anisakis type I (Anisakidae) and Hysterothylacium spp. (Raphidascaridae), detected in 601 (33.65\%) and 207 (11.59\%) specimens, respectively. In addition, very few samples of silver hake were parasitized by Contracaecum spp. (Anisakidae).

The results obtained from the nine fish species are given below, while details on prevalence, mean abundance and parasitation range for each fish species related to the variables analysed are presented in Tables 1-4. The comparative results of prevalence and mean abundance in the fish flesh are shown in Figures 1 and 2, respectively. 
Table 1. Prevalence (\%), mean abundance and $95 \%$ confidence intervals, intensity range (minimum-maximum) and number of Anisakis type I larvae in the total sample.

\begin{tabular}{|c|c|c|c|c|c|}
\hline \multirow{2}{*}{ Fish Species } & \multicolumn{5}{|c|}{ Total Sample } \\
\hline & $\mathbf{N}$ & Prevalence (\%) & Mean Abundance & Range & Number of Larvae \\
\hline Blue whiting (Micromesistius poutasou) & 153 & 53.87 & $3.87(2.02-5.72)$ & $1-219$ & 1098 \\
\hline Hake (Merluccius merluccius) & 90 & 45.00 & $10.20(2.66-17.73)$ & $1-574$ & 2042 \\
\hline Silver hake (Merlucccius bilinearis) & 69 & 59.48 & $1.42(1.06-1.78)$ & $1-6$ & 165 \\
\hline Red mullet (Mulllus barbatus) & 5 & 3.23 & $0.05(0.00-0.09)$ & $1-3$ & 7 \\
\hline Mackerel (Scomber scombrus) & 135 & 58.44 & $5.68(3.67-7.68)$ & $1-198$ & 1311 \\
\hline Chub mackerel (Scomber japonicum) & 19 & 17.59 & $1.11(0.00-2.85)$ & $1-95$ & 120 \\
\hline Horse mackerel (Trachurus trachurus) & 66 & 66.00 & $26.72(16.29-35.73)$ & $1-341$ & 2672 \\
\hline Sardine (Sardina pilchardus) & 19 & 6.76 & $0.20(0.06-033)$ & $1-16$ & 55 \\
\hline Anchovy (Engraulis encrasicolus) & 45 & 14.47 & $0.28(0.16-0.39)$ & $1-13$ & 86 \\
\hline Total & 601 & 33.65 & 3.99 & $1-574$ & 7123 \\
\hline
\end{tabular}

Table 2. Prevalence (\%) and mean abundance and 95\% confidence intervals of Anisakis type I larvae in the fish species analysed with respect to their geographic origin.

\begin{tabular}{lcccc}
\hline \multirow{2}{*}{ Fish Species } & \multicolumn{2}{c}{ Atlantic Ocean } & \multicolumn{2}{c}{ Mediterranean Sea } \\
\cline { 2 - 5 } & Prevalence (\%) & Mean Abundance & Prevalence (\%) & Mean Abundance \\
\hline Blue whiting (Micromesistius poutasou) & 77.51 & $4.83(3.08-6.58)$ & 19.13 & $2.45(0.00-6.25)$ \\
Hake (Merluccius merluccius) & 84.00 & $20.34(5.40-35.28)$ & 6.00 & - \\
Silver hake (Merlucccius bilinearis) & 59.48 & $1.42(1.06-1.78)$ & $-05(0.00-0.10)$ & - \\
Red mullet (Mullus barbatus) & - & - & 3.23 & $0.05(0.00-0.09)$ \\
Mackerel (Scomber scombrus) & 76.43 & $7.29(4.16-10.41)$ & 3.77 & $3.20(1.57-4.83)$ \\
Chub mackerel (Scomber japonicum) & 19.18 & $1.84(0.00-5.12)$ & $0.17(0.20-0.33)$ \\
Horse mackerel (Trachurus trachurus) & 100.00 & $52.50(35.26-69.74)$ & 32.00 & $0.94(0.43-1.45)$ \\
Sardine (Sardina pilchardus) & 11.43 & $0.34(0.08-0.61)$ & 2.13 & $0.05(0.00-0.12)$ \\
Anchovy (Engraulis encrasicolus) & 18.87 & $0.43(0.21-0.66)$ & 9.87 & $0.11(0.05-0.17)$ \\
\hline \multicolumn{1}{c}{ Total } & 52.90 & 4.56 & 11.92 \\
\hline
\end{tabular}

Table 3. Prevalence (\%) and mean abundance and 95\% confidence intervals of Anisakis type I larvae in the fish species analysed with respect to the microhabitat of parasitation.

\begin{tabular}{lcccc}
\hline \multirow{2}{*}{ Fish Species } & \multicolumn{2}{c}{ Prevalence (\%) } & \multicolumn{2}{c}{ Mean Abundance } \\
\cline { 2 - 5 } & Viscera & Flesh & Viscera & Flesh \\
\hline Blue whiting (Micromesistius poutasou) & 49.60 & 26.10 & $3.15(1.54-4.75)$ & $0.72(0.40-1.03)$ \\
Hake (Merluccius merluccius) & 35.00 & 29.50 & $6.50(1.15-11.84)$ & $3.70(1.51-5.99)$ \\
Silver hake (Merlucccius bilinearis) & 46.60 & 28.40 & $1.02(0.71-1.32)$ & $0.41(0.25-0.56)$ \\
Red mullet (Mullus barbatus) & 3.23 & 0.00 & $0.05(0.00-0.09)$ & 0.00 \\
Mackerel (Scomber scombrus) & 55.85 & 25.98 & $4.65(3.07-6.23)$ & $1.03(0.48-1.57)$ \\
Chub mackerel (Scomber japonicum) & 16.70 & 2.80 & $1.07(0.00-2.78)$ & $0.04(0.00-0.08)$ \\
Horse mackerel (Trachurus trachurus) & 60.00 & 28.00 & $26.72(16.81-36.63)$ & $1.40(1.05-1.75)$ \\
Sardine (Sardina pilchardus) & 5.34 & 2.14 & $0.17(0.04-0.31)$ & $<0.01(0.00-0.04)$ \\
Anchovy (Engraulis encrasicolus) & 11.90 & 4.18 & $0.26(0.12-0.34)$ & $0.22(0.09-0.38)$ \\
\hline
\end{tabular}

Table 4. Prevalence (\%) and mean abundance and 95\% confidence intervals of Anisakis type I larvae in the fish species analysed with respect to season of capture.

\begin{tabular}{lcccc}
\hline \multirow{2}{*}{\multicolumn{1}{c}{ Fish Species }} & \multicolumn{2}{c}{ Prevalence (\%) } & \multicolumn{2}{c}{ Mean Abundance } \\
\cline { 2 - 5 } & Autumn & Spring & Autumn & Spring \\
\hline Blue whiting (Micromesistius poutasou) & 47.80 & 59.30 & $4.35(2.13-6.57)$ & $3.43(0.53-6.34)$ \\
Hake (Merluccius merluccius) & 7.50 & 54.40 & $0.36(0.00-0.74)$ & $12.81(3.29-22.33)$ \\
Silver hake (Merlucccius bilinearis) & 64.30 & 55.00 & $1.75(1.15-2.35)$ & $1.12(0.70-1.53)$ \\
Red mullet (Mullus barbatus) & 5.30 & 1.20 & $0.08(0.00-0.17)$ & $0.01(0.00-0.04)$ \\
Mackerel (Scomber scombrus) & 62.35 & 56.16 & $4.47(3.05-5.88)$ & $7.75(2.85-12.66)$ \\
Chub mackerel (Scomber japonicum) & 19.20 & 22.00 & $1.84(0.00-5.12)$ & $0.26(0.11-0.41)$ \\
Sardine (Sardina pilchardus) & 3.19 & 8.70 & $0.07(0.00-0.18)$ & $0.26(0.06-0.46)$ \\
Anchovy (Engraulis encrasicolus) & 7.69 & 17.28 & $0.22(0.00-0.51)$ & $0.30(0.18-0.42)$ \\
\hline
\end{tabular}




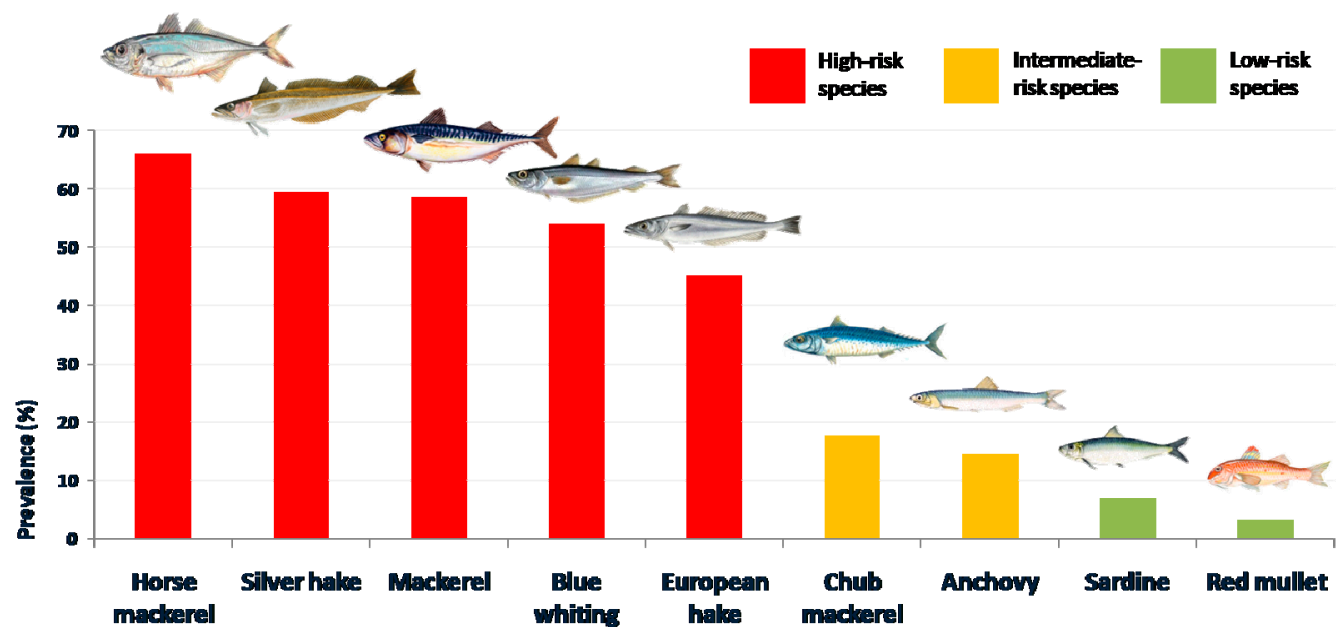

Figure 1. Classification of the fish species based on the prevalence (\%) of Anisakis type I larvae.

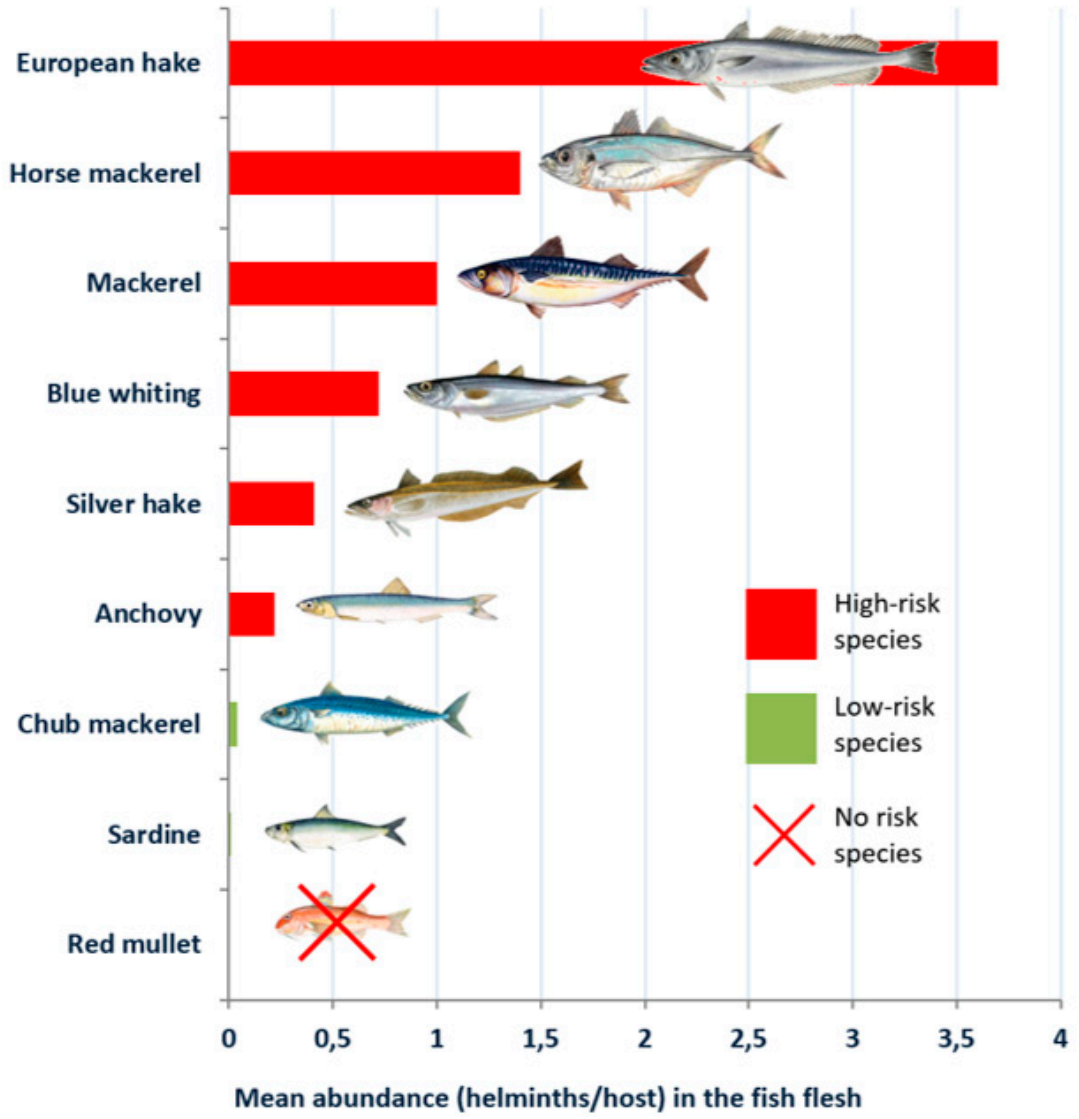

Figure 2. Classification of the fish species based on the mean abundance (helminths/host) of Anisakis type I larvae observed in the fish flesh.

\subsection{Blue Whiting (Micromesistius poutassou)}

A total of 158 specimens (55.63\%) was parasitized by helminth larvae; $53.87 \%$ of the fish were parasitized by Anisakis type I and $11.97 \%$ by Hysterothylacium.spp.

The Atlantic fish were more parasitized than the Mediterranean specimens, with a significant statistical difference $\left(\chi^{2}=91.537 ; \mathrm{P}<0.0001 ; \mathrm{df}=1\right)$. Higher presence of larvae was noted in viscera $(49.60 \%)$ than in the flesh $(26.10 \%)$, also statistically significant $\left(\chi^{2}=32.600 ; \mathrm{P}<0.0001 ; \mathrm{df}=1\right)$. No significant difference in prevalence was detected in spring $(59.30 \%)$ compared to autumn $(47.80 \%)$. 
The mean abundance for the total blue whiting sample was 4.51 helminths per host, being higher for Anisakis type I (3.87) than in Hysterothylacium spp. (0.64). Focusing on Anisakis type I larvae, a larger number of larvae per host was found in the Atlantic fish in respect to the Mediterranean $(\mathrm{U}=3375$; $\mathrm{P}<0.0001 ; \mathrm{df}=1)$. A higher abundance was also found in the viscera (3.15) than in the flesh $(0.72)$ $(\mathrm{Z}=-7.646 ; \mathrm{P}<0.0001 ; \mathrm{df}=1)$. In respect to the season, results were very similar in autumn $(4.35)$ and spring (3.43), without significant difference.

Prevalence was influenced by three factors, that is, fish length, origin and season, when the total sample was considered $\left(\chi^{2}=133.103 ; \mathrm{P}=0.0001 ; \mathrm{df}=3\right)$. Moreover, the number of days that passed between fishing and the analysis influenced the presence of larvae in the flesh $\left(\chi^{2}=5.119 ; \mathrm{P}=0.24\right.$; $\mathrm{df}=8)$. The Spearman test showed that weight $(\mathrm{Rho}=0.251 ; \mathrm{P}=0.0001 ; \mathrm{df}=1)$ and length $(\mathrm{Rho}=0.382$; $\mathrm{P}=0.0001 ; \mathrm{df}=1$ ) influenced abundance when all the samples were analysed but not when only Atlantic fish were considered, due to the high prevalence found in both, large and small specimens.

\subsection{European Hake (Merluccius merluccius)}

In total 91 of 200 specimens (45.50\%) were infected by larvae, of which $90(45.00 \%)$ were parasitized by Anisakis type I and only $2(1.00 \%)$ by Hysterotylacium spp.

Fish from the Atlantic was more parasitized than Mediterranean fish $\left(\chi^{2}=119.78 ; \mathrm{P}<0.0001\right.$; $\mathrm{df}=1)$. Larvae were found more frequently in the viscera $(35.00 \%)$ than in the flesh $(29.50 \%)$, although this difference was not significant. Concerning the season of capture, a significant difference was detected $\left(\chi^{2}=26.547 ; \mathrm{P}<0.0001 ; \mathrm{df}=1\right)$, with a higher parasite presence in spring (54.40) than in autumn (7.50).

Considering all the specimens, a mean abundance of 10.22 was found, although the number of larvae per host was higher in the case of Anisakis type I (10.20) than in Hysterothylacium spp. (0.01). The Atlantic sample showed a higher mean abundance (20.34) than the Mediterranean (0.05) $(U=940$; $\mathrm{P}<0.0001 ; \mathrm{df}=1)$. The mean abundance in the viscera (6.50) was higher than in the flesh (3.70), although this difference was not significant. The number of helminths per host also depended on the season $(\mathrm{U}=1620 ; \mathrm{P}<0.0001 ; \mathrm{df}=1)$, with a higher mean abundance in spring (12.81) than in autumn (0.36).

Binary logistic regression (BLR) analyses showed that the origin and the length of the fish influenced the prevalence when the entire sample is considered $\left(\chi^{2}=157.453 ; \mathrm{P}=0.0001 ; \mathrm{df}=2\right)$. In addition, the number of days that passed between fishing and the analysis influenced the presence of larvae in the flesh $\left(\chi^{2}=16.381 ; \mathrm{P}<0.0001 ; \mathrm{df}=1\right)$, also when the entire sample is considered. Fish size also influenced on the mean abundance, since the Spearman test showed that both weight $($ Rho $=0.280 ; \mathrm{P}=0.0001 ; \mathrm{df}=1)$ and length $(\mathrm{Rho}=0.319 ; \mathrm{P}=0.0001 ; \mathrm{df}=1)$ influence abundance when the entire sample was analysed, suggesting that larger specimens had a higher number of larvae.

\subsection{Silver Hake (Merluccius bilinearis)}

All the silver hake specimens included in this study were caught in the North-West Atlantic Ocean. Consequently, the origin was not considered as a variable of study in this case. In total 69 specimens $(59.48 \%$ ) were found parasitized by Anisakis type I larvae. No larvae belonging to the genus Hysterothylacium spp. were identified in this fish species. However, 4 specimens were parasitized by larvae belonging to the genus Contracaecum (3.44\%).

Considering only the genus Anisakis, a higher prevalence and mean abundance was found in the viscera $(46.60 \% ; 1.02)$ than in the flesh $(28.40 \% ; 0.41)$, with statistically significant differences both in the case of prevalence $\left(\chi^{2}=7.356 ; \mathrm{P}<0.0001 ; \mathrm{df}=1\right)$ and mean abundance $(\mathrm{Z}=-3.772 ; \mathrm{P}<0.0001 ; \mathrm{df}=1)$. Higher prevalence and mean abundance were detected in autumn $(64.30 \% ; 1.75$ helminths/host) than in spring $(55.00 \%$; 1.12 helminths/host), although the differences were not statistically significant.

BLR analyses showed that prevalence was not influenced by any factor. Considering only the parasitized fish, no influence of the number of days that passed between fishing and the analysis was 
detected. Moreover, length $(\mathrm{Rho}=0.259 ; \mathrm{P}=0.005 ; \mathrm{df}=1)$ and weight $(\mathrm{Rho}=0.258 ; \mathrm{P}=0.005 ; \mathrm{df}=1)$ also had a positive influence on abundance.

\subsection{Red Mullet (Mullus barbatus)}

The origin was not taken into account as a variable of this study, as the specimens available originated only from the Mediterranean Sea. A total of 43 specimens (27.74\%) were parasitized by helminth larvae. In this case both prevalence and abundance of Hysterothylacium spp. $(25.16 \% ; 0.58)$ were higher than those of Anisakis type I ( $3.23 \%$; 0.05$)$.

No Anisakis larvae were found in the flesh. Anisakis type I prevalence and abundance were lower in spring $(1.20 \% ; 0.01)$ than in autumn $(5.30 \% ; 0.08)$, although this difference was not significant.

Due to the low number of parasitized hosts, it was not possible to carry out a detailed helminthological study as well as an analysis of the influence of extrinsic and intrinsic factors on the infection by Anisakis type I.

\subsection{Mackerel (Scomber scombrus)}

A total of 135 (58.44\%) mackerels was found parasitized, all of them harbouring Anisakis type I larvae and only $11(4.76 \%)$ carrying Hysterothylacium spp. larvae.

Significant differences were found concerning fish origin $\left(\chi^{2}=47.347 ; \mathrm{P}<0.0001 ; \mathrm{df}=1\right)$, showing a higher prevalence in the fish originating from the Atlantic Ocean $(76.43 \%)$ than in the fish from the Mediterranean Sea $(30.77 \%)$. The statistical analysis showed a higher percentage of parasitation in the viscera $(55.85 \%)$ than in the flesh $(25.98 \%)\left(\chi^{2}=42.630 ; \mathrm{P}<0.0001 ; \mathrm{df}=1\right)$. In contrast, no statistically significant differences were observed between season of capture, with a prevalence of $62.35 \%$ in autumn and a prevalence of $56.16 \%$ in spring.

A mean abundance of 5.68 Anisakis type I larvae per host was observed, in contrast to Hysterothylacium spp. that had the mean abundance of 0.10 helminths/host only. The mean abundance of Anisakis type I larvae differed in respect to the origin, being higher in the Atlantic (7.29) in comparison to the Mediterranean (3.20) $(\mathrm{U}=3647 ; \mathrm{P}<0.0001 ; \mathrm{df}=1)$. Just as in the case of prevalence, a higher mean abundance was detected in the viscera (4.65) than in the flesh (1.03) $(Z=8318 ; P<0.0001$; $\mathrm{df}=1$ ). Significant differences were not observed according to the season of capture, showing a mean abundance of 4.47 in spring and 7.75 in autumn.

BLR analysis showed that prevalence was decisively influenced by fish length and origin $\left(\chi^{2}=86.245 ; \mathrm{P}=0.0001 ; \mathrm{df}=2\right)$. The number of days that passed between fishing and the analysis influenced the finding of larvae in the flesh $\left(\chi^{2}=22.458 ; \mathrm{P}<0.0001 ; \mathrm{df}=1\right)$. The Spearman test revealed the influence of length $($ Rho $=0.365 ; \mathrm{P}=0.0001 ; \mathrm{df}=1)$ and weight $(\mathrm{Rho}=0.549 ; \mathrm{P}=0.0001 ; \mathrm{df}=1)$ on the abundance of larvae.

\subsection{Chub Mackerel (Scomber japonicus)}

The only helminth larvae found in this fish species was identified as Anisakis type I. A total of 19 specimens $(17.59 \%)$ was parasitized, with a mean abundance of 1.11 .

Fish from the Atlantic Ocean was more parasitized (19.18\%) than the Mediterranean fish (14.29\%), although this difference was not significant. A higher presence of larvae was found in the viscera $(16.70 \%)$ than in the flesh $(2.80 \%)\left(\chi^{2}=10.338 ; \mathrm{P}=0.0009 ; \mathrm{df}=1\right)$. Concerning the season of capture, in spring the prevalence was higher $(22.00 \%)$ than in autumn $(19.20 \%)$, although the difference was not significant.

Just as in the case of prevalence, the mean abundance was higher in the Atlantic Ocean (1.84) than in the Mediterranean Sea (0.17), although the difference was not significant. The mean abundance was higher in the viscera (1.07) than in the flesh (0.04) but without statistical significance. However, the mean abundance was greater in fish captured in autumn (1.84) than in fish captured in spring (0.26) but without statistical differences. 
BLR analysis showed that the prevalence of the entire sample was not influenced by any factor. Likewise, the number of days that passed between fishing and the analysis did not have any influence on the prevalence. Moreover, the statistical analysis also showed that none of the extrinsic and intrinsic factors considered influenced the mean abundance.

\subsection{Horse Mackerel (Trachurus trachurus)}

A total of 66 horse mackerel specimens was parasitized by Anisakis type I larvae (66.00\%) and 54 (54.00\%) were parasitized by Hysterothylacium spp.

All specimens originating from the Atlantic were found parasitized by Anisakis type I larvae and only $16(32.00 \%)$ of those from the Mediterranean $\left(\chi^{2}=48.529 ; \mathrm{P}<0.0001 ; \mathrm{df}=1\right)$. A higher presence of the parasite was found in the viscera $(60.00 \%)$ compared to the flesh $(28.00 \%)$, although this difference was not statistically significant.

Mean abundance of the total sample was 34.6, being higher for Anisakis type I (26.72) than Hysterothylacium spp. (7.90). The mean abundance of Anisakis type I was much higher in the fish from the Atlantic (52.50) than from the Mediterranean (0.94) $(\mathrm{U}=18 ; \mathrm{P}=0.0001 ; \mathrm{df}=1)$. Moreover, the mean abundance in the viscera (26.72) was higher than in the flesh $(1.40)(Z=7.063 ; P=0.0001 ; d f=1)$.

BLR analysis showed that none of the factors considered, influenced the prevalence. Concerning the presence of parasites in the flesh and the number of days that passed between the catch and the analysis of the specimens, no relationship was found.

Anisakis type I burden of the total batch was influenced by both, length $($ Rho $=0.815 ; \mathrm{p}=0.0001$; $\mathrm{df}=1$ ) and weight (Rho $=0.794 ; \mathrm{P}=0.0001 ; \mathrm{df}=1$ ). However, when considering the origin of the fish, only the batch from the Atlantic reflected positive correlations between the mean abundance and the length (Rho $=0.519 ; \mathrm{P}=0.0001 ; \mathrm{df}=1)$ and the weight $(\mathrm{Rho}=0.453 ; \mathrm{P}=0.0001 ; \mathrm{df}=1)$.

\subsection{Sardine (Sardina pilchardus)}

A total of 74 (26.33\%) sardines were found parasitized. Hysetorhylacium spp. larvae were most prevalent, parasitizing 67 specimens $(23.84 \%)$, whereas only 19 specimens $(6.76 \%)$ were parasitized by Anisakis type I.

The prevalence of Anisakis type I was higher in the Atlantic fish (11.43\%) than in the Mediterranean $(2.13 \%)\left(\chi^{2}=4.774 ; \mathrm{P}=0.029 ; \mathrm{df}=1\right)$ and in spring $(8.70 \%)$ than in autumn $(3.19 \%)$, although this difference was not significant. Furthermore, there was a higher prevalence in the viscera (5.34\%) than in the flesh $(2.14 \%)$, barely being statistically significant $\left(\chi^{2}=4.007 ; \mathrm{P}=0.0451 ; \mathrm{df}=2\right)$.

The mean abundance of the total batch was 2.94, with a very low number of Anisakis type I (0.20) and a higher value of Hysterothylacium spp. (2.75). The total larval burden was higher in the Atlantic fish (0.34) than in that from the Mediterranean $(0.05)(\mathrm{U}=8950 ; \mathrm{P}=0.002 ; \mathrm{df}=1)$. The total mean abundance was higher in the viscera $(0.17)$ than in the flesh $(<0.01)(Z=-6379 ; P<0.0001 ; d f=1)$, in spite of the low number of larvae found. No differences were detected concerning the seasons.

Season of capture and fish length influenced the total prevalence $\left(\chi^{2}=56.844 ; \mathrm{P}<0.0001 ; \mathrm{df}=2\right)$. Conversely, there was no influence of the numbers of days that passed on the prevalence in the flesh. Furthermore, the Spearman test showed the influence of origin (Rho $=-0.185 ; \mathrm{p}=0.002)$, length (Rho $=0.353 ; \mathrm{P}<0.001 ; \mathrm{df}=1)$ and weight $(\mathrm{Rho}=0.320 ; \mathrm{P}<0.001 ; \mathrm{df}=1)$ on the mean abundance.

\subsection{Anchovy (Engraulis encrasicolus)}

In total 84 anchovy specimens (27.01\%) were parasitized, $14.47 \%$ by Anisakis type I and $18.33 \%$ by Hysterothylacium spp.

Fish originating from the Atlantic were more parasitized by Anisakis type I $(18.87 \%)$ than those from the Mediterranean (9.87\%) $\left(\chi^{2}=5.086 ; \mathrm{P}=0.024 ; \mathrm{df}=1\right)$. A higher presence of larvae was observed in viscera $(11.90 \%)$ than in the flesh $(4.18 \%)\left(\chi^{2}=12.527 ; \mathrm{P}=0.0004 ; \mathrm{df}=1\right)$. A higher prevalence of infection was also detected in spring $(17.28 \%)$ than in autumn $(7.69 \%)\left(\chi^{2}=4.774 ; \mathrm{P}=0.029 ; \mathrm{df}=1\right)$. 
The mean abundance for the total sample was 1.80, being higher for Anisakis type I (0.28) than Hysterothylacium spp. (1.53). The total mean abundance of Anisakis type I was higher in the Atlantic fish (0.43) than in the Mediterranean $(0.11)(\mathrm{U}=10936 ; \mathrm{P}=0.018 ; \mathrm{df}=1)$. A higher mean abundance was also found in the viscera $(0.26)$ than in the flesh $(0.22)(\mathrm{Z}=-4.123 ; \mathrm{P}<0.0001 ; \mathrm{df}=1)$. The larval burden in spring (0.30) was higher than in autumn $(0.22)(\mathrm{U}=9052 ; \mathrm{P}=0.030 ; \mathrm{df}=1)$.

BLR analysis showed that prevalence of Anisakis type I was influenced by the season of capture and fish weight, when considering the total sample $\left(\chi^{2}=30.549 ; \mathrm{P}<0.0001 ; \mathrm{df}=2\right)$. However, the number of days that passed between fishing and the analysis did not influence the prevalence in the flesh. In contrast, the total mean abundance was influenced by origin $(\mathrm{Rho}=0.135 ; \mathrm{P}=0.018 ; \mathrm{df}=1)$, season $(\mathrm{Rho}=123 ; \mathrm{P}<0.030 ; \mathrm{df}=1)$, length $(\mathrm{Rho}=0.216 ; \mathrm{P}<0.0001 ; \mathrm{df}=1)$ and weight $(\mathrm{Rho}=0.265$; $\mathrm{P}<0.0001 ; \mathrm{df}=1)$.

\section{Discussion}

The present study provides epidemiological data on the presence of Anisakis type I and other anisakid $\mathrm{L}_{3}$ larvae in fish frequently consumed in Spain, in order to assess the risk of anisakidosis through fresh fish purchased in the Spanish supermarkets. Moreover, the presence of larvae of other nematode species (Hysterothylacium spp.), resembling anisakids to a non-expert, parasitizing these fish species is reported, posing additional issues associated to the quality of the product. It is important to highlight, as the supermarkets included in the study all belong to nationwide chains that sell fish originating from almost the same fishery areas, that the results obtained in this study can be extrapolated to all Spanish supermarkets.

Results revealed that all the fish species were parasitized by Anisakis type I larvae with a global prevalence of $33.65 \%$. Anisakis species have been reported in a wide range of marine pelagic fish and cephalopods [16-18], most of them encompassing an important part of the human diet. As fish is considered a staple of the healthy diet, particularly in Spain [19], the results reported herein pinpoint the fish species with a high risk of infection.

Nevertheless, there are considerable differences in the infection risk depending on the fish species analysed: i) "high-risk" species, with a high rate of infection; ii) "intermediate or low-risk" species, with a low rate of infection or with a scarce presence of larvae in the edible parts.

Five of the studied species can be classified as "high risk" species: the blue whiting, the European hake, the silver hake, the mackerel and the horse mackerel. Considering the prevalence and abundance registered, all of them could represent a high risk of infection when consumed raw, marinated or poorly cooked, if not being adequately frozen beforehand. In general, this observation is in accordance with other results previously reported [20-30].

Results concerning the blue whiting, assessed previously in depth by Madrid et al. [31], are in agreement with other studies, confirming this as one of the most parasitized fish species [20-22]. The blue whiting is one of the main fin fish species consumed in Spain [32], due to its low cost and its easy mode of preparation. The same goes for the European hake, another of the fin fish analysed in which a significant prevalence was detected, also reported by other authors [23-25]. The silver hake, of which there are scarcely similar studies in the literature [23], had a high prevalence, although the abundance was lower in comparison to the other "high risk" species. In this fish species, the finding of Contracaeum spp. $\mathrm{L}_{3}$ stands out, since this was the only species in which this anisakid was found. Nevertheless, in spite of the reports of anisakidosis cases caused by Contracaecum spp. larvae [33], their potential pathogenicity in humans is under discussion [34].

The mackerel and the horse mackerel, the two "high risk" pelagic fish species, consumed frequently marinated or pickled in Spain, were two of the most infected species. Other authors have also reported high values of parasitation both in the mackerel [10,35] and the horse mackerel [26-28], suggesting that these species may involve a serious source of infection if safety measures are not correctly applied. A more extensive study concerning anisakid larvae in the mackerel was carried out by Madrid et al. [29]. 
In respect to the number of larvae per host, a total mean abundance of 3.99 was observed, with large differences depending on the fish species. The horse mackerel was the species with the highest mean abundance in the present study, being well above the rest. The European hake, the mackerel and the blue whiting also presented a high mean abundance. The helminth burden was in accordance with previous studies evidencing a high mean abundance in these "high risk" fish species. However, in the case of the horse mackerel, the mean abundance was greater than in some previous reports $[27,28,30]$.

The other fish species studied (the red mullet, the chub mackerel, the sardine and the anchovy) can a priori be considered "intermediate or low-risk" species, due to the lower values of prevalence and abundance in comparison to the others. In the case of the red mullet, there are only few works focusing on the presence of anisakids, although all of them reported a low prevalence of Anisakis spp. [36,37]. A more extensive study on helminth parasites of the red mullet was carried out by Debenedetti et al. [38].

The chub mackerel is a pelagic fish species frequently consumed in Japan, where a very high prevalence was reported [39]. In Spain, this fish species is less frequent, often being confused with the mackerel due to their similar appearance. In the present study, a relatively high prevalence was found, lower than the prevalence recorded by other authors for the same fishing areas [40], although the lower presence of larvae in the flesh makes it possible to consider this species an "intermediate-risk" fish. Consequently, it is important for the consumer to differentiate between the mackerel and the chub mackerel, given their different risk level for anisakidosis, high for the former and intermediate for the latter.

The sardine is generally considered a fish with a low risk of anisakiosis, since many authors have either reported the absence of Anisakis spp. larvae [35,41] or a very low prevalence [42,43]. In the present study, a low prevalence and abundance was found, although the values are higher in comparison to the previous studies. However, some cases of anisakiosis due to the consumption of raw sardines have been reported in Spain [44,45].

The anchovy is one of the most popular fish consumed in Spain, mainly marinated in vinegar, usually for $24 \mathrm{~h}$, known as "boquerones in vinegar." Therefore, it is also considered the main source of anisakidosis in this country through the consumption of this home-made dish [6,45]. In the present study, a prevalence of $14.47 \%$ was observed, which is apparently low but may still involve a serious risk of infection. Other authors reported a higher prevalence and abundance in this fish from central areas of the Mediterranean, such as the NE part of the Mediterranean Sea and the Atlantic waters, showing percentages of parasitation and abundances in general higher than those reported herein $[10,46,47]$. However, some studies reported the absence of anisakids or a prevalence below $10 \%$, suggesting that anchovies are rarely infected [35,48-50]. Nevertheless, the prevalence of larvae in the flesh is relatively high in comparison to the other "low-risk" fish. Therefore, taking into account that this fish species is usually consumed raw and marinated in vinegar, the potential presence of larvae in the flesh has to be considered. In addition to this, some experiments suggest that the consumption of anchovies in vinegar parasitized with Anisakis sp. larvae may pose a risk to sensitized individuals, even if the larvae are killed by freezing $[15,50]$. Consequently, the anchovy should be included in the "high-risk" species group.

Given the origin of the fish species analysed, specimens originating from the Atlantic, when compared to the Mediterranean, were more parasitized, usually with statistically significant differences. In total $52.90 \%$ of the fish captured in the Atlantic were parasitized by Anisakis type I larvae, whereas the percentage was only 11.92 from the Mediterranean. This finding is in accordance with previous studies carry out in various teleost species $[11,21,26,42,51-53]$. Therefore, the origin of the fish should be taken into consideration by consumers in order to minimize the infection risk.

The host size (length and weight) was an influent factor for parasitation in almost all the fish species analysed, suggesting that larger specimens may involve a higher risk of infection. Only in the case of the horse mackerel, this factor was not significant, although such lack of significance is mainly due to the high prevalence observed and the differences in size depending on the origin. This made 
it impossible to analyse the entire sample as a whole. There are numerous works that reported the influence of this factor on some fish species $[46,48,51,54-57]$. The host size is directly related to the age of the host and therefore, the high level of parasitation in older specimens may be due to the accumulation of larvae along time and the higher probabilities of infection, leading to a higher level of abundance and prevalence [57].

The prevalence observed in spring was, in general, higher than in autumn, although this factor does not seem to play an important role, since the European hake and the anchovy were the only species in which seasonal differences were significant. These differences are probably related to the seasonal patterns of migration of these fish species, as well as to the effect of the season on the presence of euphausiid crustaceans in the environment, which encompass an important item in the food chain of these hosts [23]. Several studies have reported seasonal differences of parasitation $[27,48,57,58]$. It is noteworthy that in some of the species analysed the prevalence was higher in one season, while the abundance was higher in the other one, as other authors also reported [59], probably due to a regulation mechanism of the parasite in order to close its life cycle.

In all the species analysed, a higher presence of the parasite was detected in the viscera than in the flesh, although in the most parasitized species (the blue whiting, the European hake, the silver hake, the mackerel and the horse mackerel), the prevalence in the flesh was remarkable, within a range of $25.98 \%-29.50 \%$. The mean abundance also was noteworthy, particularly in the case of the mackerel and the horse mackerel, with a range of 1-3.70 larvae per host. Considering the life cycle of anisakids [60], the preferred parasitation site of larvae is the viscera and other body cavities, although it is known that they are able to migrate and to spiralise in the flesh of the host [7]. Considering that the flesh is the main edible part, the presence of larvae in the flesh involves a higher risk for consumers. Nevertheless, the presence of the larvae in the viscera should not be ignored, since the flesh can easily be contaminated when the specimen is eviscerated and handled.

Furthermore, a significant effect of the fish storage on the presence of larvae in the flesh was found in the blue whiting, the European hake and the mackerel, being suggestive of the migratory capability of these larvae evaluated through the number of days that passed after the catch. Other authors have also reported that Anisakis spp. larvae are able to migrate from the visceral organs to the flesh after the death of the host, suggesting that this movement may be facilitated by the cold storage or processing of uneviscerated fish [53]. In contrast, other experiments suggest that keeping the fish at low temperature could reduce larval migration [61]. Particularly, in the present study, the species in which this correlation was significant were those with the highest prevalence and abundance values. The accumulation of larvae in the viscera could promote their migration to the flesh. In the case of the horse mackerel this effect was not found, which can be explained by the large number of larvae detected in both sites, making it impossible to establish the correlation through the statistical analysis. Therefore, the capability of migration in this fish species should not be ruled out.

The finding of other nematode species cannot be overlooked, not only because of their potential capacity of causing pathology in humans but also because of their deleterious effect at a commercial level. The high percentage of Hysterotylacium spp. larvae observed in some fish species must be seriously considered. Their high prevalence and abundance, particularly in the horse mackerel, are higher than in previous studies [26,54]. In contrast, other fish species, also highly parasitized by Anisakis type I, showed a lower prevalence (i.e., the blue whiting, the mackerel and the European hake) or were not parasitized at all (i.e., the silver hake and the chub mackerel) by Hysterotylacium spp. larvae. Moreover, in the fish species in which a low or very low prevalence and abundance of Anisakis type I larvae were found (i.e. the red mullet, the sardine and the anchovy), a higher presence of Hysterotylacium spp. larvae was detected, with a prevalence range of $18-25 \%$. These data are in accordance with previous studies, which in general also recorded a high presence of this parasite in particular fish species $[37,41,49]$. It is true that this nematode is considered not potentially harmful for human health, with only isolated cases reported in the literature related to its presence in the human gut $[62,63]$. However, they do seem to produce a significant pressure on the host visceral 
organs [64], causing a pathogenic effect in live fish as well as an economic loss given the devaluation of the commercial product. Consequently, consumers must be warned about the presence and the potential effect of the parasite, avoiding the possible confusion with Anisakis spp. larvae.

\section{Materials and Methods}

\subsection{Samples}

A total of 1.786 specimens belonging to nine fish species was selected for this survey, all of them species frequently consumed in Spain. The species included in the survey were the blue whiting (Micromesistius poutassou), the European hake (Merluccius merluccius), the silver hake (M. bilinearis), the red mullet (Mullus barbatus), the mackerel (Scomber scombrus), the chub mackerel (S. japonicus), the horse mackerel (Trachurus trachurus), the sardine (Sardina pilchardus) and the anchovy (Engraulis encrasicolus). These species and the number of specimens are shown in Table 5. All the specimens were purchased in branches of four nationwide Spanish supermarket chains located in València and its metropolitan area. The fish analysed were obtained in the period from 2006 to 2015, as part of a project on the potential risk of human anisakidosis through the consumption of fresh fish in Spain, conducted by the Parasites and Health Research Group of the Department of Pharmacy and Pharmaceutical Technology and Parasitology, at University of València (Spain). Some of these results have been previously published $[29,31,38]$.

The area of origin, Atlantic, Food and Agriculture Organization of the United Nations [FAO] zones 21 and 27 (subareas IV, VIII and IX) or Mediterranean Sea, FAO zone 37.1, division 1.1, as well as the date of capture were taken from the fish label at the time of purchase. The samples were chosen at random, fresh and non-eviscerated and in the laboratory were kept in a fridge at $4{ }^{\circ} \mathrm{C}$ until dissection. Each sample was weighed and the total length was measured. Finally, specimens were also grouped according to season of capture, distinguishing two periods: spring and autumn. This variable was not studied in the case of the horse mackerel, as the sample was obtained in spring only. The number of specimens analysed with respect to the origin and the season of capture is shown in Table 5. Table 6 presents data of the weight and length range, as well as the number of days that passed between capture and analysis.

Table 5. Origin and season of capture of the sample.

\begin{tabular}{lccccc}
\hline \multicolumn{1}{c}{ Fish Species } & N & Atlantic & Mediterranean & Autumn & Spring \\
\hline Blue whiting (Micromesistius poutasou) & 284 & 169 & 115 & 134 & 150 \\
Hake (Merluccius merluccius) & 200 & 100 & 100 & 40 & 160 \\
Silver hake (Merlucccius bilinearis) & 116 & 116 & - & 56 & 60 \\
Red mullet (Mullus barbatus) & 155 & - & 155 & 75 & 80 \\
Mackerel (Scomber scombrus) & 231 & 140 & 91 & 85 & 146 \\
Chub mackerel (Scomber japonicum) & 108 & 73 & 35 & 58 & 50 \\
Horse mackerel (Trachurus trachurus) & 100 & 50 & 50 & - & 100 \\
Sardine (Sardina pilchardus) & 281 & 140 & 141 & 94 & 187 \\
Anchovy (Engraulis encrasicolus) & 311 & 159 & 152 & 91 & 220 \\
\hline \multicolumn{1}{c}{ Total } & 1786 & 947 & 839 & 657 & 1129 \\
\hline
\end{tabular}

Table 6. Weight, length and days passed between capture and analysis of the sample.

\begin{tabular}{lccc}
\hline \multicolumn{1}{c}{ Fish Species } & Weight Range (g) & Length Range (cm) & Days Range \\
\hline Blue whiting (Micromesistius poutasou) & $17.58-145.20$ & $14.50-28.60$ & $1-8$ \\
Hake (Merluccius merluccius) & $43.63-549.6$ & $19.40-41.50$ & $1-6$ \\
Silver hake (Merlucccius bilinearis) & $51.44-215.92$ & $19.00-32.50$ & $1-8$ \\
Red mullet (Mullus barbatus) & $11.24-85.60$ & $10.60-21.00$ & $1-5$ \\
Mackerel (Scomber scombrus) & $29.96-466.80$ & $16.60-25.70$ & $1-6$ \\
Chub mackerel (Scomber japonicum) & $62.72-511.80$ & $15.00-39.20$ & $1-6$ \\
Horse mackerel (Trachurus trachurus) & $16.10-37.00$ & $29.90-360.40$ & $1-7$ \\
Sardine (Sardina pilchardus) & $8.80-120.61$ & $10.60-25.70$ & $1-4$ \\
Anchovy (Engraulis encrasicolus) & $7.10-39.10$ & $10.50-18.20$ & $1-5$ \\
\hline
\end{tabular}




\subsection{Fish Inspection}

Each specimen was analysed for the presence of anisakid larvae, after conventional dissection. The viscera and flesh of each specimen were placed in two different Petri dishes and examined separately. The viscera were dissected under a stereoscopic microscope and the flesh, after a previous visual inspection, underwent artificial enzymatic digestion [65]. Resulting product from the digestion was also examined under a stereoscopic microscope.

\subsection{Morphological Identification}

All the anisakids found were identified according to the morphological characters described in the literature [66-68]. The main characteristics considered for these classifications were the position of the excretory pore, the arrangement and separation of the digestive tract into oesophagus, ventricle and the presence/absence of structures such as intestinal caeca and oesophageal appendix, as well as the shape of the tail.

\subsection{Statistical Analysis}

The number of infected hosts, range of parasitation, prevalence and mean abundance were analysed according to Bush et al. [69] for the total of anisakids found, as well as for each of the genera identified. Moreover, these parameters were also calculated for the site of parasitation (viscera and flesh), the season and origin of capture. In the case of the mean abundance, the confidence interval (95\% CI), using the bootstrap method, was also calculated [70,71].

The study was carried out solely for the isolation and identification of Anisakis spp. larvae, as it is the only species that survives artificial digestion and consequently poses a risk of human infection. The analysis comprised the comparison of prevalence ( $\chi^{2}$ test) and abundances (Mann-Whitney (U) test) and sites of parasitation (Wilcoxon $(Z)$ test). The potential risk of human anisakidosis was assessed analysing the influence of intrinsic (weight and length) and extrinsic (origin and season) factors on the prevalence and abundance of Anisakis spp. larvae, by binary logistic regression (BLR) for prevalence and the Spearman test (Rho) for abundance. Furthermore, the potential influence of the number of days after capture (which corresponds to the theoretical day of consumption, 1-8 days) on the presence of larvae in the flesh was also analysed by BLR, considering parasitized hosts only. Statistical significance was established at $\mathrm{P}<0.05$. Statistical analyses were carried out using StatView 5.0 (SAS Institute Inc., Cary, North Carolina, USA) and SPSS 19.0 for Windows (SPSS Inc., Chicago, Illinois, USA) software packages.

\section{Conclusions}

The present study presents an overview on the prevalence and the risk of anisakid larvae in fresh fish frequently consumed in Spain. As the fish was purchased in selected supermarket chains present in the entire Spanish territory, the results obtained in the study area can be extrapolated to the entire country. Global prevalence and abundance of parasitation by Anisakis larvae were found to be high, with the blue whiting, the European hake, the silver hake, the mackerel, the horse mackerel and the anchovy presenting a serious risk of Anisakis spp. infection.

The fish originating from the Atlantic and specimens with a larger size present the highest risk, not only because these groups showed the highest values of infection but also prevalence and abundance higher in the fish flesh. In addition to this, the capacity of larval migration after prolonged storage in some of these "high-risk" species was observed, suggesting that immediate evisceration after capture recommendable as an effective measure to prevent parasite presence.

To minimize the risk of anisakiosis, consumers have to follow the preventive measures recommended by Commission Regulation (EU) No1276/2011 [12] and by Spanish Royal Decree $1420 / 2006$ [13]: freezing fish at $-20^{\circ} \mathrm{C}$, for at least $24 \mathrm{~h}$ or cooking the fish until reaching a core temperature of $60-70^{\circ} \mathrm{C}$ for 5 to $10 \mathrm{~min}$.. The infection risk can be minimized if traceability data 
available at the fish selling point are taken into account, paying attention to the specific name of the fish, the place of capture (FAO area) and the day of capture. It is preferably to choose fish caught in the Mediterranean, avoiding large specimens, particularly those of the blue whiting, the hake, the mackerel and the horse mackerel.

Author Contributions: Conceptualization, M.V.F. Formal Analysis, M.V.F., E.M. and A.L.D.; Investigation, M.V.F., A.L.D., E.M., M.T., F.C., F.G.G. and S.S.; Resources, M.V.F. and M.T.; Data Curation, M.V.F.; Writing-Original Draft Preparation, A.L.D. and M.V.F.; Writing—Review \& Editing, A.L.D. and M.V.F.; Visualization, M.V.F., A.L.D., E.M., M.T., F.C., F.G.G. and S.S.D.; Supervision, M.V.F.; Project Administration, M.V.F. All authors read and approved the final version of the manuscript. All the authors have contributed other works focusing on the risk analysis of foodborne parasitic zoonoses through the consumption of fresh and frozen fish in Spain.

Funding: This research received no external funding.

Conflicts of Interest: The authors declare no conflict of interest.

\section{References}

1. Serrano-Moliner, M.; Morales-Suarez-Varela, M.; Valero, M.A. Epidemiology and management of foodborne nematodiasis in the European Union, systematic review 2000-2016. Pathog. Glob. Health 2018, 112, 1-10. [CrossRef] [PubMed]

2. Hochberg, N.S.; Hamer, D. Anisakidosis: Perils of the Deep. Clin. Infect. Dis. 2010, 51, 806-812. [CrossRef] [PubMed]

3. European Food Safety Authority (EFSA). Scientific opinion on risk assessment of parasites in fishery products. EFSA Panel on Biological Hazards (BIOHAZ). EFSA J. 2010, 8, 1543. [CrossRef]

4. Mazzucco, W.; Raia, D.D.; Marotta, C.; Costa, A.; Ferrantelli, V.; Vitale, F.; Casuccio, A. Anisakis sensitization in different population groups and public health impact: A systematic review. PLoS ONE 2018, 13, e0203671. [CrossRef]

5. Baird, F.J.; Gasser, R.; Jabbar, A.; Lopata, A.L. Foodborne anisakiasis and allergy. Mol. Cell Probes 2014, 28, 164-174. [CrossRef] [PubMed]

6. Bao, M.; Pierce, G.J.; Pascual, S.; González-Muñoz, M.; Mattiuci, S.; Mladineo, I.; Cipriani, P.; Bušelić, I.; Strachan, N.J. Assessing the risk of an emerging zoonosis of worldwide concern: Anisakiasis. Sci. Rep. 2017, 13, 43699. [CrossRef] [PubMed]

7. Buchmann, K.; Mehrdana, F. Effects of anisakid nematodes Anisakis simplex (s.1.), Pseudoterranova decipiens (s.1.) and Contracaecum osculatum (s.1.) on fish and consumer health. FAWPAR 2016, 4, 13-22. [CrossRef]

8. Mattiucci, S.; Cipriani, P.; Levsen, A.; Paoletti, M.; Nascetti, G. Molecular epidemiology of Anisakis and Anisakiasis: An Ecological and Evolutionary Road Map. Adv. Parasitol. 2018, 99, 93-263. [CrossRef]

9. Romero, M.C.; Valero, A.; Navarro-Moll, M.C.; Martín-Sánchez, J. Experimental comparison of pathogenic potential of two sibling species Anisakis simplex s.s. and Anisakis pegreffii in Wistar rat. Trop. Med. Int. Health 2013, 18, 979-984. [CrossRef]

10. Levsen, A.; Svanevik, C.S.; Cipriani, P.; Mattiucci, S.; Gay, M.; Hastie, L.C.; Bušelić, I.; Mladineo, I.; Karl, H.G.N.D.; Ostermeyer, U.; et al. A survey of zoonotic nematodes of commercial key fish species from major European fishing grounds-Introducing the FP7 PARASITE exposure assessment study. Fish. Res. 2018, 202, 4-21. [CrossRef]

11. Herrador, Z.; Daschner, A.; Perteguer, M.J.; Benito, A. Epidemiological scenario of anisakidosis in Spain based on associated hospitalizations: The tipping point of the iceberg. Clin. Inf. Dis. 2018. [CrossRef]

12. European Commission. Commission Regulation (EU) No 1276/2011 of 8 December 2011 amending Annex III to Regulation (EC) No 853/2004 of the European Parliament and of the Council as regards the treatment to kill viable parasites in fishery products for human consumption. Off. J. Eur. Union L 2011, 327, $39-41$.

13. Real Decreto 1420/2006, de 1 de diciembre, sobre prevención de la parasitosis por anisakis en productos de la pesca suministrados por establecimientos que sirven comida a los consumidores finales o a colectividades. Boletín Oficial Estado 2006, 302, 44547-44549. (In Spanish)

14. Sánchez-Alonso, I.; Carballeda-Sangia, N.; González-Muñoz, M.; Navas, A.; Arcos, S.C.; Mendizábal, A.; Tejada, M.; Careche, M. Pathogenic potential of Anisakis $\mathrm{L}_{3}$ after freezing in domestic freezers. Food Control 2018, 84, 61-69. [CrossRef] 
15. Solas, M.T.; García, M.L.; De las Heras, C.; Rodriguez-Mahillo, A.I.; Gonzalez-Muñoz, M.; Moneo, I.; Mendizábal, A.; Tejada, M. Anisakis simplex antigens in fresh and frozen-thawed muscle of anchovies in vinegar. Food Sci. Technol. Int. 2008, 15, 139-148. [CrossRef]

16. Klimpel, S.; Palm, H.W.; Rückert, S.; Piatkowski, U. The life cycle of Anisakis simplex in the Norwegian Deep (northern North Sea). Parasitol. Res. 2004, 94, 1-9. [CrossRef] [PubMed]

17. Kuhn, T.; Hailer, F.; Palm, H.W.; Klimpel, S. Global assessment of molecularly identified Anisakis Dujardin, 1845 (Nematoda: Anisakidae) in their teleost intermediate hosts. Folia Parasitol. 2013, 60, 123-134. [CrossRef] [PubMed]

18. Gregori, M.; Roura, Á.; Abollo, E.; González, Á.F.; Pascual, S. Anisakis simplex complex (Nematoda: Anisakidae) in zooplankton communities from temperate NE Atlantic waters. J. Nat. Hist. 2015, 49, 755-773. [CrossRef]

19. Ministerio de Agricultura, Pesca y Alimentación. Informe del Consumo de Alimentación en España. 2017. Available online: https:/ / www.mapa.gob.es/images/es/informeanualdeconsumoalimentario2017_tcm30456186.pdf (accessed on 8 December 2018).

20. Fernández, M.; Aznar, F.J.; Montero, F.E.; Raga, J.A. Endoparasites of the blue whiting, Micromesistius poutassou from north-west Spain. J. Helminthol. 2005, 79, 15-21. [CrossRef] [PubMed]

21. Molina-Fernández, D.; Rubio-Calvo, D.; Adroher, F.J.; Benítez, R. Molecular epidemiology of Anisakis spp. in blue whiting Micromesistius poutassou in eastern waters of Spain, western Mediterranean Sea. Int. J. Food Microbiol. 2018, 282, 49-56. [CrossRef] [PubMed]

22. Ojeda-Torrejón, A.J.; Collado-Jara, A.; Salasváxquez, M. Investigación de parásitos en bacaladillascapturadas en la bahía de Cádiz. Med. Gen. 2001, 38, 808-811.

23. Marcogliese, D.J. Geographic and temporal variations in levels of anisakid nematode larvae among fishes in the Gulf of St. Lawrence, eastern Canada. Can. Tech. Rep. Fish. Aquat. Sci. 1995, 2029, 1-16.

24. Pascual, S.; Rodríguez, H.; Pierce, G.J.; Hastie, L.C.; González, A.F. The NE Atlantic European hake: A neglected high exposure risk for zoonotic parasites in European fish markets. Fish. Res. 2018, 202, 69-78. [CrossRef]

25. Cipriani, P.; Sbaraglia, G.L.; Paoletti, M.; Giulietti, L.; Bellisario, B.; Palomba, M.; Bušelić, I.; Mladineo, I.; Nascetti, G.; Mattiucci, S. The Mediterranean European hake, Merluccius merluccius: Detecting drivers influencing the Anisakis spp. larvae distribution. Fish. Res. 2018, 202, 78-89. [CrossRef]

26. Cruz, C.; Vaz, A.; Saraiva, A. Larval anisakids from horse mackerel in Portugal. Helminthologia 2005, 42, 3-7.

27. Abattouy, N.; Valero, A.; Lozano, J.; Benajiba, N.H.; Martín-Sánchez, J. Epidemiology and molecular identification of Anisakis pegreffii (Nematoda: Anisakidae) in the horse mackerel Trachurus trachurus from northern Morocco. J. Helminthol. 2014, 88, 257-263. [CrossRef] [PubMed]

28. Shawket, N.; El Aasri, A.; Elmadhi, Y.; M’Bareck, I.; El Kharrim, K.; Belghyti, D. Anisakis simplex (Nematoda: Anisakidae) from horse mackerel (Trachurus trachurus) in Atlantic coast of Morocco. Asian Pac. J. Trop. Dis. 2017, 7, 463-466. [CrossRef]

29. Madrid, E.; Gil, F.; García, M.; Debenedetti, A.L.; Trelis, M.; Fuentes, M. Potential risk analysis of human anisakiasis through the consumption of mackerel, Scomber scombrus, sold at Spanish supermarkets. Food Control 2016, 66, 300-305. [CrossRef]

30. Eissa, A.E.; Showehdib, M.L.; Ismailc, M.M.; El-Naasd, A.S.; Abu-Mharae, A.A.; Abolghaitf, S.K. Identification and prevalence of Anisakis pegreffii and A. pegreffii $\times$ A. simplex (s.s.) hybrid genotype larvae in Atlantic horse mackerel (Trachurus trachurus) from some North African Mediterranean coasts. Egypt. J. Aquat. Res. 2018, 44, 21-27. [CrossRef]

31. Madrid, E.; Galán-Puchades, M.T.; Fuentes, M. Risk analysis of human anisakidosis through the consumption of the blue whiting, Micromesistius poutassou, sold at Spanish supermarkets. Foodborne Pathog. Dis. 2012, 9, 934-938. [CrossRef]

32. Ministerio de Agricultura, Alimentación y Medio Ambiente. Informe Sobre Abastecimiento de Pescado Blanco. 2015. Available online: https://www.mapa.gob.es/va/pesca/temas/mercados-economiapesquera/informesobreabastecimientodepescadoblanco_tcm39-290622.pdf (accessed on 8 December 2018).

33. Shamsi, S.; Butcher, A.R. First report of human anisakidosis in Australia. Med. J. Aust. 2011, 194, $199-200$. [PubMed] 
34. Galeano, N.A. Evaluación del Potencial Zoonótico de Contracaecum spp. (Nematoda: Anisakidae) e Hysterothylacium spp. (Nematoda: Raphidascarididae) Como Agentes de Anisakidosis Humana. Ph.D. Thesis, Universidad Nacional del Sur, Bahía Blanca, Argentina, 2017.

35. Gutiérrez-Galindo, J.F.; Osanz-Mur, A.C.; Moraventura, M.T. Occurrence and infection dynamics of anisakid larvae in Scomber scombrus, Trachurus trachurus, Sardina pilchardus, and Engraulis encrasicolus from Tarragona (NE Spain). Food Control 2010, 21, 1550-1555. [CrossRef]

36. Serracca, L.; Cencetti, E.; Battistini, R.; Rossini, I.; Prearo, M.; Pavoletti, E.; Fioravanti, M.L.; Righetti, M.; Di Donfrancesco, B.; Ercolini, C. Survey on the presence of Anisakis and Hysterothylacium larvae in fishes and squids caught in Ligurian Sea. Vet. Parasitol. 2013, 196, 547-551. [CrossRef] [PubMed]

37. Barcala, E.; Ramilo, A.; Ortega, N.; Picó, G.; Abollo, E.; Pascual, S.; Muñoz, P. Occurrence of Anisakis and Hysterothylacium larvae in commercial fish from Balearic Sea (Western Mediterranean Sea). Parasitol. Res. 2018, 117, 4003-4012. [CrossRef] [PubMed]

38. Debenedetti, A.L.; Madrid, E.; Fuentes, M.V. Study of helminth parasites in the red mullet, Mullus barbatus, from the Mediterranean Sea and acquired in greater València, Spain. Rev. Ibero-Latinoam. Parasitol. 2010, 72, 118-123.

39. Suzuki, J.; Murata, R.; Hosaka, M.; Araki, J. Risk factors for human Anisakis infection and association between the geographic origins of Scomber japonicus and anisakid nematodes. Int. J. Food Microbiol. 2010, 137, 88-93. [CrossRef]

40. Costa, G.; Pontes, T.; Mattiucci, S.; D'Amélio, S. The occurrence and infection dynamics of Anisakis larvae in the black-scabbard fish, Aphanopus carbo, chub mackerel, Scomber japonicus, and oceanic horse mackerel, Trachurus picturatus from Madeira, Portugal. J. Helminthol. 2003, 77, 163-166. [CrossRef]

41. Rello, F.J.; Adroher, F.J.; Valero, A. Hysterothylacium aduncum, the only anisakid parasite of sardines (Sardina pilchardus) from the southern and eastern coasts of Spain. Parasitol. Res. 2008, 104, 117-121. [CrossRef]

42. Sanmartín, M.L.; Quinteiro, P.; Iglesias, R.; Santamaría, M.T.; Leiro, J.; Ubeira, F.M. Nematodos Parásitos de Peces de las Costas Gallegas; Ediciones Díaz Santos: Madrid, Spain, 1994; p. 88.

43. Cavallero, S.; Magnabosco, C.; Civettini, M.; Boffo, L.; Mingarelli, G.; Buratti, P.; Giovanardi, O.; Fortuna, C.M.; Arcangeli, G. Survey of Anisakis sp. and Hysterothylacium sp. in sardines and anchovies from the North Adriatic Sea. Int. J. Food. Microbiol. 2015, 200, 18-21. [CrossRef]

44. López-Vélez, R.; García, A.; Barros, C.; Manzarbeitia, F.; Oñate, J.M. Anisakiasis in Spain. Report of 3 cases. Enferm. Infecc. Microbiol. Clin. 1992, 10, 158-161.

45. Berger, S. Infectious Diseases of Spain; Gideon Informatics: Los Angeles, CA, USA, 2018; pp. $27-28$.

46. De Liberato, C.; Bossù, T.; Scaramozzino, P.; Ncolini, G.; Ceddia, P.; Mallozzi, S.; Cavallero, S.; D’Amelio, S. Presence of anisakid larvae in the European anchovy, Engraulis encrasicolus, fished off the Tyrrhenian coast of central Italy. J. Food Prot. 2013, 76, 1643-1648. [CrossRef]

47. Cipriani, P.; Sbaraglia, G.L.; Palomba, M.; Giulietti, L.; Bellisario, B.; Bušelić, I.; Mladineo, I.; Cheleschi, R.; Nascetti, G.; Mattiucci, S. Anisakis pegreffii (Nematoda: Anisakidae) in the European anchovy Engraulis encrasicolus, from the Mediterranean Sea: Fishing ground as a predictor of the parasite distribution. Fish. Res. 2018, 202, 59-68. [CrossRef]

48. Rello, F.J.; Adroher, F.J.; Benítez, R.; Valero, A. The fishing area as a possible indicator of the infection by anisakids in anchovies (Engraulis encrasicolus) from southwestern Europe. Int. J. Food Microbiol. 2009, 129, 277-281. [CrossRef] [PubMed]

49. Gazzonis, A.L.; Cavallero, S.; Zanzani, S.A.; Olivieri, E.; Malandra, R.; Ranghieri, V.; D'Amelio, S.; Manfredi, M.T. Anisakis sp. and Hysterothylacium sp. larvae in anchovies (Engraulis encrasicolus) and chub mackerel (Scomber colias) in the Mediterranean Sea: Molecular identification and risk factors. Food Control 2017, 80, 366-373. [CrossRef]

50. Rodríguez-Domínguez, H.; González, A.F.; Abollo, E.; Pascual, S. Re-evaluation of anchovies (Engraulis encrasicolus) as an important risk factor for sensitization to zoonotic nematodes in Spain. Fish. Res. 2018, 202, 49-58. [CrossRef]

51. Abaunza, P.; Villamor, B.; Perez, J.R. Infestation by larvae of Anisakis simplex (Nematoda: Ascaridata) in horse mackerel, Trachurus trachurus, and Atlantic mackerel, Scomber scombrus, in ICES Divisions VIIIb, VIIIc and Ixa (N-NW of Spain). Sci. Mar. 1995, 59, 223-233.

52. Silva, M.; Eiras, J. Occurrence of Anisakis sp. in fishes off the Portuguese West coast and evaluation of its zoonotic potential. bull. Eur. Assoc. Fish Pathol. 2003, 23, 13-17. 
53. Abollo, E.; Gestal, C.; Pascual, S. Anisakis infestation in marine fish and cephalopods from Galician waters: An updated perspective. Parasitol. Res. 2001, 87, 492-499. [CrossRef]

54. Adroher, F.J.; Valero, A.; Ruiz-Valero, J.; Iglesias, L. Larval anisakids (Nematoda: Ascaridoidea) in horse mackerel (Trachurus trachurus) from the fish market in Granada (Spain). Parasitol. Res. 1996, 82, 253-256. [CrossRef]

55. Valero, A.; López-Cuello, M.M.; Benítez, R.; Adroher, F.J. Anisakis spp. in European hake, Merluccius merluccius (L.) from the Atlantic off north-west Africa and the Mediterranean off southern Spain. Acta Parasitol. 2006, 51, 209-212. [CrossRef]

56. Soric, R.E.; Miramontes-Sequeiros, L.C.; Miron, L. Palanca-Soler, A. Morphometrics for Anisakiasis diagnosis in the North Atlantic horse mackerel (Trachurus trachurus). Sci. Parasitol. 2012, 12, 77-81.

57. Strømnes, E.; Andersen, K. "Spring rise" of whaleworm (Anisakis simplex; Nematoda, Ascaridoidea) thirdstage larvae in some fish species from Norwegian waters. Parasitol. Res. 2000, 86, 619-624. [CrossRef] [PubMed]

58. De la Torre Molina, R.; Pérez Aparicio, J.; Hernández-Bienes, M.; Jurado-Pérez, R.; Martínez Ruso, A.; Morales Franco, E. Anisakiasis in fresh fish sold in the north of Córdoba. Revista Espanola Salud Publica 2000, 74, 517-526.

59. Gómez-Mateos, M.; Valero, A.; Morales-Yuste, M.; Martín-Sánchez, J. Molecular epidemiology and risk factors for Anisakis simplex s.l. infection in blue whiting (Micromesistius poutassou) in a confluence zone of the Atlantic and Mediterranean: Differences between A. simplex s.s. and A. pegreffii. Int. J. Food Microbiol. 2016, 232, 111-116. [CrossRef] [PubMed]

60. Nagasawa, K. The Life Cycle of Anisakis simplex: A Review. In Intestinal Anisakiasis in Japan; Ishikura, H., Kikuchi, K., Eds.; Springer: Tokyo, Japan, 2010; pp. 31-40.

61. Cipriani, P.; Acerra, V.; Bellisario, B.; Sbaragli, G.L.; Cheleschi, R.; Nascetti, G.; Mattiucci, S. Larval migration of the zoonotic parasite Anisakis pegreffii (Nematoda: Anisakidae) in European anchovy, Engraulis encrasicolus: Implications to seafood safety. Food Control 2016, 59, 148-157. [CrossRef]

62. Yagi, K.; Nagasawa, K.; Ishikura, H.; Nagasawa, A.; Sato, N.; Kikuchi, K.; Ishikura, H. Female worm Hysterothylacium aduncum excreted from human: A case report. Jpn. J Parasitol. 1996, 45, 12-23.

63. González-Amores, Y.; Clavijo-Frutos, E.; Salas-Casanova, C.; Alcain-Martínez, G. Direct parasitologial diagnosis of infection with Hysterothylacium aduncum in a patient with epigastralgia. Revista Espanola Enfermedades Digestivas 2015, 107, 699-700.

64. Skovgaard, A.; Bahlool, Q.Z.M.; Munk, P.; Berge, T.; Buchmann, K. Infection of North Sea cod, Gadus morhua L., larvae with the parasitic nematode Hysterothylacium aduncum Rudolphi. J. Plankton Res. 2011, 33, 1311-1316. [CrossRef]

65. Llarena-Reino, M.; Piñeiro, C.; Antonio, J.; Outeriño, L.; Vello, C.; González, A.F.; Pascual, S. Optimization of the pepsin digestion method for anisakids inspection in the fishing industry. Vet. Parasitol. 2013, 191, 276-283. [CrossRef]

66. Grabda, J. Marine Fish Parasitology. An Outline; PWN-Polish scientific Publisher: Warszawa, Poland, 1991; p. 306.

67. Anderson, R.C.; Chabaud, A.G.; Willmott, S. Keys to the Nematode Parasites of Vertebrates, Archival Volume; CAB International: Wallingford, England, 2009; p. 463.

68. Gibbons, L.M. Keys to the Nematode Parasites of Vertebrates, Supplementari Volume; CAB International: Wallingford, England, 2010; p. 416.

69. Bush, A.O.; Lafferty, K.D.; Lotz, J.M.; Shostak, A.W. Parasitology meets ecology on its own terms: Margolis et al. revisited. J. Parasitol. 1997, 83, 575-583. [CrossRef]

70. Rózsa, L.; Reiczigel, J.; Majoros, G. Quantifying parasites in samples of hosts. J. Parasitol. 2000, 86, $228-232$. [CrossRef]

71. Shvydka, S.; Sarabeev, V.; Estruch, V.D.; Cadarso-Suárez, C. Optimum sample size to estimate mean parasite abundance in fish parasite surveys. Helminthologia 2018, 55, 52-59. [CrossRef]

(C) 2019 by the authors. Licensee MDPI, Basel, Switzerland. This article is an open access article distributed under the terms and conditions of the Creative Commons Attribution (CC BY) license (http:/ / creativecommons.org/licenses/by/4.0/). 